\title{
Research Square \\ Multimorbidity Clustering of the Emergency Department Patient Flow: Impact Analysis of New Unscheduled Care Clinics
}

Adrien Wartelle ( $\square$ adrien.wartelle@ch-troyes.fr)

Centre Hospitalier de Troyes

Farah Mourad-Chehade

University of Technology of Troyes

Farouk Yalaoui

University of Technology of Troyes

Hélène Questiaux

Centre Hospitalier de Troyes

Thomas Monneret

Etablissement Aubois des Soins Immédiats

Ghilain Solivau

Etablissement Aubois des Soins Immédiats

Jan Chrusciel

Centre Hospitalier de Troyes

Antoine Duclos

Hospices Civils de Lyon

David Laplanche

Centre Hospitalier de Troyes

Stéphane Sanchez

Centre Hospitalier de Troyes

\section{Research Article}

Keywords: Emergency Medical Services, Cluster Analysis, Multimorbidity Patterns, Retrospective Studies, Health Services Research

Posted Date: December 28th, 2020

DOI: https://doi.org/10.21203/rs.3.rs-125764/v1

License: (a) (i) This work is licensed under a Creative Commons Attribution 4.0 International License.

Read Full License 
Version of Record: A version of this preprint was published at PLOS ONE on January 31 st, 2022. See the published version at https://doi.org/10.1371/journal.pone.0262914. 
1 Title : Multimorbidity clustering of the emergency department patient flow : impact analysis of

\section{2 new unscheduled care clinics}

3 Authors : Adrien Wartelle, $\mathrm{MSc}^{1,2, *}$, Farah Mourad-Chehade, $\mathrm{PhD}^{1}$, Farouk Yalaoui, $\mathrm{PhD}^{1}$, Hélène

4 Questiaux, $\mathrm{MD}^{3}$, Thomas Monneret, $\mathrm{MD}^{4}$, Ghislain Soliveau, $\mathrm{MD}, \mathrm{PhD}^{4}$, Jan Chrusciel, $\mathrm{MD}^{2}$, Antoine

5 Duclos, MD, $\mathrm{PhD}^{5,6,7}$, David Laplanche, $\mathrm{MD}^{2}$, Stéphane Sanchez, MD, MPH².

$6 \quad{ }^{1}$ Université Technologique de Troyes, Institut Charles Delaunay, Troyes, F-10000, France

$7 \quad{ }^{2}$ Centre Hospitalier de Troyes, Health Services and Performance Research Lab, Troyes, F-10000,

8 France

$9 \quad{ }^{3}$ Centre Hospitalier de Troyes, Emergency Department, Troyes, F-10000, France

$10 \quad{ }^{4}$ Etablissement Aubois des Soins Immédiats, Troyes, F-10000, France

$11 \quad{ }^{5}$ Hospices Civils de Lyon, Health Data Department, Lyon, F-69003, France

12 Université Claude Bernard Lyon 1, Health Services and Performance Research Lab (HESPER

13 EA7425), F-69008 Lyon, France

$14{ }^{7}$ Brigham and Women's Hospital, Harvard Medical School, Center for Surgery and Public Health,

15 Boston, MA, USA

16 * Corresponding authors informations :

17 Address: Centre Hospitalier de Troyes, Health Services and Performance Research Lab,

18101 Av Anatole France 10000 Troyes, F-10000, France ; Phone: 003325494801 / E-mail:

19 adrien.wartelle@ch-troyes.fr

20 Complete author information

21 Adrien Wartelle, MSc, $\left({ }^{*}\right.$ Corresponding author $)$

22 PhD Student,

23 Addresses: Centre Hospitalier de Troyes, Health Services and Performance Research Lab,

24101 Av Anatole France 10000 Troyes, F-10000, France ; Phone: 003325494801 / E-mail: 
Université Technologique de Troyes, Institut Charles Delaunay, 12 rue Marie Curie, 10000 Troyes, F10000, France; Phone: 0033257156 77/ E-mail: adrien.wartelle@utt.fr

Farad Mourad-Chehade, PhD,

Associate Professor,

Université Technologique de Troyes, Institut Charles Delaunay, 12 rue Marie Curie, 10000 Troyes, F-

31 10000, France; Phone: 00333257156 77/ E-mail: farah.chehade@utt.fr

32 Farouk Yalaoui, PhD,

33 Professor,

34 Université Technologique de Troyes, Institut Charles Delaunay, 12 rue Marie Curie, 10000 Troyes, F35 10000, France; Phone: 0033325715626 / E-mail: farouk.yalaoui@utt.fr

\section{Hélène Questiaux, MD}

37 Emergency Physician,

38 Addresses: Centre Hospitalier de Troyes, Emergency Department, 101 Av Anatole France 10000

39 Troyes, F-10000, France; Phone: 0033325497025 / E-mail: helene.questiaux@ch-troyes.fr

40 Thomas Monneret, MD,

41 Emergency Physician

42 Addresses: Etablissement Aubois des Soins Immédiats, 4 Rue Chaim Soutine 10000 Troyes, F-10000,

43 France; Phone: 0033325494949 / E-mail: thomas.monneret@ch-troyes.fr

\section{Ghilain Solivau, MD,}

45 Emergency Physician,

Addresses: Etablissement Aubois des Soins Immédiats, 4 Rue Chaim Soutine 10000 Troyes, F-10000,

France; Phone: 0033325494949 / E-mail: drsoliveau@gmail.com

Jan Chrusciel, MD, MPH

49

Public Health Physician,

50 Addresses: Centre Hospitalier de Troyes, Health Services and Performance Research Lab,

51101 Av Anatole France 10000 Troyes, F-10000, France; Phone: 0033325494801 / E-mail:

52 jan.chrusciel@ch-troyes.fr

53 Antoine Duclos, MD, PhD, 
Public Health Physician, Professor,

55 Addresses : Hospices Civils de Lyon, Health Data Department, 3 Quai des Célestins 69002 Lyon, F-

56 69002, France; Phone: 0033472115771 / E-mail: antoine.duclos@chu-lyon.fr

57 David Laplanche, MD,

58 Public Health Physician,

59 Addresses: Centre Hospitalier de Troyes, Health Services and Performance Research Lab,

60101 Av Anatole France 10000 Troyes, F-10000, France; Phone: 0033325494801 / E-mail:

61 david.laplanche@ch-troyes.fr

62 Stéphane Sanchez, MD, MPH

63 Public Health Physician,

64 Address: Centre Hospitalier de Troyes, Health Services and Performance Research Lab,

65101 Av Anatole France 10000 Troyes, F-10000, France; Phone: 0033325494801 / E-mail:

66 stephane.sanchez@ch-troyes.fr

67

68

69

70

71

72

73

74

75

76

77 
Background: In France, the number of admissions to emergency departments doubled between 1996 and 2016, leading to overcrowding. To cope with the resultant overcrowding, redirecting patients to new healthcare services is a viable solution, to spread demand more evenly across available healthcare delivery points, and render care more efficient. The goal of this study was to analyse the impact of opening new unscheduled care services on variations in patient attendance at a large emergency department.

Methods: We performed a before-and-after study investigating the use of unscheduled care services in the Aube Department (Eastern France), focusing on emergency department attendance of Troyes Hospital. We applied a hierarchical clustering based on co-occurrence of diagnoses, to divide the population into different multimorbidity profiles and study their temporal trends. A multivariate logistic regression model was constructed to adjust the period effect for appropriate confounders.

Results: In total, 120,718 visits to the emergency department were recorded over a 24 -month period (2018-2019), and 14 clusters were identified accounting for $94.76 \%$ of all visits. The before-and-after analysis showed a decrease of 57.95 visits per week in 7 specific clusters, while the consumption of unscheduled health care services increased by 328.12 visits per week.

Conclusions: Using an innovative and reliable methodology to evaluate changes in patient flow through the emergency department, our results could help to inform public health policy regarding the implementation of unscheduled care services, to ease pressure on emergency departments.

Keywords: Emergency Medical Services, Cluster Analysis, Multimorbidity Patterns, Retrospective Studies, Health Services Research 
104 In France, admissions to Emergency Departments (ED) doubled between 1996 and 2016, increasing

105 from 10 to 20 million visits annually, corresponding to an average growth of $3.5 \%$ per year [1]. This

106 has led to overcrowding and saturation of EDs, with negative repercussions on quality of care [2] and

107 on working conditions for healthcare professionals. Given the complex, systemic nature of this

108 problem, expanding ED capacity and employing more staff are insufficient solutions [3]. Only a

109 detailed study of healthcare needs, including analysis of patient flow and patient expectations, will

110 enable the development of adequate solutions for healthcare delivery [4-7]. While EDs can re-organize

111 internal procedures to optimize patient flow and delivery of care $[8,9]$, such changes do not stem the

112 ever increasing tide of patients coming to the ED. Redirecting "avoidable" ED visits towards other

113 healthcare services, notably Unscheduled Care Services (UCS), which are alternative clinics that can

114 treat patients with low acuity conditions [10-15], is therefore one of the main responses proposed by

115 current reforms $[16,17]$.

116 To evaluate the impact of new UCS on demand for ED care, it is necessary to quantify patient inflow

117 and characterise the dynamics of patient flow through the ED [18, 19]. Most previous studies in this

118 field have focused on a global evaluation of avoided ED visits and the resultant economical savings

119 due the lower cost of UCS [10-15]. Segmentation of the complex patient flow using a classification of

120 ED visits could help to characterize the nature of patient profiles avoided, and consequently, better

121 understand temporal variations in ED attendance [20].

122 In this regard, the analysis of multimorbidity patterns is an appropriate tool to model the complexity of

123 patients in terms of the diversity and statistical co-occurrences of their health conditions [21-25].

124 Usually applied on populations of complex and chronic patients in a high multimorbidity context,

125 many opportunities still reside to extend this analysis on broader contexts like diseases trajectories of

126 patients $[26,27]$.

127 In this context, segmenting the overall ED patient flow using the diagnoses from the visits and disease

128 clusters, could be an innovative and original approach to evaluating the structure of, and trends in ED 
patient flow $[22,28,29]$. We hypothesized that modelling the profiles of patients attending the ED

130 could enable more detailed analysis of the impact of UCS on ED attendance. The aim of this study

131 was thus to investigate the impact of opening new UCS on patient flow through the largest ED in the

132 Aube Department (France).

\section{METHODS}

\section{Study design and population}

135 We performed a before-and-after study of the consumption of unscheduled care in the Aube

136 Department in Eastern France, particularly at the ED of the hospital of Troyes. The event of interest

137 that changed the organisation of delivery of unscheduled care in Troyes was the opening between

138 October and November 2018 of two new UCS, offering services akin to convenient care clinics [30].

139 The population under study was the whole population of patients attending the ED of Troyes hospital

140 from 01 May 2017 to 28 April 2019. Troyes hospital is the largest hospital in the Aube Department,

141 with a population of 310,000 inhabitants and a medical density of 234.1 physicians per 100,000

142 inhabitants that is in the lowest quarter of the Departments in France. The hospital has 442 medical

143 beds, 127 surgical beds, and 63 beds dedicated to gynecology/obstetrics. In 2018, there were a total of

$14462,082 \mathrm{ED}$ visits, and an average rate of use of 250 to 330 visits per 1,000 inhabitants within the

145 hospital's catchment area. With $>45,000$ annual ED visits, according to national statistics [31], the ED

146 of Troyes hospital is classed as having a very high volume of activity. The 2-year study period was

147 chosen to account for seasonal variations each year, without being impacted by the restructuration of

148 the ED circuit that was introduced nationally in 2016 [9].

\section{Measured Variables}

150 The primary endpoint was the difference in patient flow, measured in visits per week, before and after

151 the opening of two new UCS, at the level of subgroups formed using clustering methods.

152 Three major types of information were recorded: 
- Information about the patient stay, visit identifier, patient identifier, date of arrival at the ED and in subsequent wards, and the triage circuit followed at arrival. The triage circuit can be either the long circuit (normal evaluation and management), or the short (fast-track) circuit, i.e. a pathway for assessment and treatment of low-severity patients (usually minor injuries or benign medical conditions). We recorded discharge destination from the ED, patient status using the Patient State (PS) classification previously developed by our group [9] and indicating patient severity. Finally, if the patient was admitted to the hospital, the primary diagnosis was recorded according to the International Classification of Diseases $10^{\text {th }}$ revision (ICD10). examinations. (i.e. town or postal code). \\ 167 Statistical analysis}

168 A multimorbidity clustering method was developed and applied to determine the spectrum of patient

169 profiles according to clinical characteristics. The detailed method is available online as Supplementary

170 Methods S1 - Additional File 1. Using the co-occurrences of ICD10 diagnoses with block level

171 representation, we applied a Hierarchical Agglomerative Clustering (HAC) [32] with a new measure of 172 similarity, namely the relative risk:

$$
R_{i j}=\frac{p_{i j}}{p_{i} p_{j}}
$$

174 where $p_{i j}$ designates the probability of diagnoses $i$ and $j$ co-occurring in sets of patients 'visits less 175 than 6 months apart, and $p_{i}$ and $p_{j}$ are the marginal probabilities of occurrences that are used to weight 176 the relation [33]. Here, the number of clusters was determined by the maximisation of a membership ratio (MR) criterion: 
$M R=\frac{R R_{\text {intra }}}{R R_{\text {inter }}}(2)$

where $\mathrm{RR}_{\text {intra }}$ designates the average of the relative risk of a block with the other blocks of its cluster, and where $\mathrm{RR}_{\text {inter }}$ designates the maximum average of the relative risk of a block with a cluster other than its own. Using this criterion, clusters were obtained, ordered by the size of the patient population concerned and named based on analysis of the blocks of diagnoses content. Relevant information was summarized using means and standard deviations, median and quartiles, and number and percentage. The content of the blocks of diagnoses and the values of $R R_{\text {intra }}$ and $R R_{\text {inter }}$ for each cluster were also analysed.

Differential analysis was performed on the rates of weekly ED visits before and after the opening of the UCS, to identify clusters showing a significant decrease, using Fisher's F test for linear trends. The significance level used was $\mathrm{p}<0.05$ and the sign \pm is used to indicate the standard deviation of a temporal series in conjunction with its mean. A multivariate logistic regression model of the probability of a visit belonging to a cluster on the decline, was constructed, adjusting for confounders. The final model was selected using backward selection, based on minimisation of the Akaike Information Criterion (AIC) [34]. The equation of the model retained was:

$$
\operatorname{Logit}(p)=\alpha+\omega P e+\gamma R+V^{\prime} \rho+X^{\prime} \beta \text { (6) }
$$

where $\mathrm{p}$ is the probability of belonging, alpha is the constant, $\mathrm{Pe}$ is the period (before or after), $\mathrm{R}$ indicates whether the visit was followed by readmission within 7 days, $\mathrm{V}$ is a visit-related information vector including the triage circuit and the quantity of prescriptions of drugs and exams, and $\mathrm{X}$ is a patient-related vector, including the age category, sex, and patient status at arrival at the ED.

In parallel, data regarding unscheduled ambulatory care from all healthcare establishments in the Department was recorded based on the statistics of the national health information database. Overall trends in patient flow were studied for the period 2016 to 2019 and put in perspective with the results of our analyses. 
204 During the 2-year study period, 120,718 visits to the ED were recorded, involving 75,279 patients; 205114,391 of these visits $(94.76 \%$ ) were retained for the present analysis (see Figure 1). These involved 20672,666 patients (96.53\%), a total of 150 blocks of diagnoses, 2750 complete ICD10 diagnostic codes 207 and an average of $1.47 \pm 0.96$ diagnostic occurrences per patient. A total of 6,199 visits $(5.16 \%)$, 208 involving 5459 patients (7.25\%), were excluded from the clustering analysis due to missing ICD10 209 diagnostic codes, and a further $208(0.17 \%)$ because of an insufficient number of occurrences of the 210 block, defined as a minimum of 10 for the purposes of this study.

211 Cluster analysis aggregated the 114,391 visits into 14 clusters. The populations of these clusters 212 ranged from 1,807 to 14,232 patients (see Table 1, Supplementary Table S2 - Additional File 1 and 213 Figure 2). The overall MR was 1.67 , with a $R R_{\text {intra }}$ value of 1.54 , and a $R R_{\text {inter }}$ value of 0.92 . Clusters 1 214 and 3 were the most heterogeneous, with local MRs of 1.23 and 1.34, in contrast with other clusters 215 where the MR was above 1.62. Most of the clusters were characterized by the heterogeneity of the 216 groups in terms of age, with standard deviations ranging from 20.96 to 28.86 years.

217 Clusters 1 and 3 were largely composed of older populations, with an average age of 58.44 and 49.51 218 years respectively. They were characterized by chronic diseases and symptoms related to aging. In 219 these clusters, we noted a high rate of use of medications, biological tests and radiological 220 examinations with a mean of 4.58 and 3.25 drugs respectively: as well as 2.79 and 2.15 biological tests 221 and 1.48 and 1.35 radiological examinations respectively. In addition, management times were longer 222 than in other clusters, with averages of respectively 261.33 , and 233.90 minutes. Hospital admission 223 rates further to the ED visit were also the highest, at $44 \%$, and $33 \%$, and involved a lower rate of 224 patients with PS1 status (namely outpatients with moderate medical treatment), at respectively 53\% 225 and $65 \%$. They were the only clusters with more marked use of the long triage circuit, with usage 226 ratios (short circuit to long circuit) of 0.36 and 0.61.

227 Cluster 2 comprised a majority of women (69\%) while clusters 5, 7, 9, 10, 13 comprised a majority of 228 men (proportions between 57 and 62\%). Cluster 2 is related to gynaecological problems (related to 
pregnancy, menstruation) and digestive problems. Clusters 5, 7, 9, 10, 13 were characterised by

230 trauma and at-risk behaviours.

231 Cluster 4 is characterised by seasonal infectious diseases and a young population with an average age

232 of 20.77 years. In particular, this cluster comprised 6,286 visits with patients aged under 5 years,

233 accounting for $43.84 \%$ of the total visits in this cluster, and $49.60 \%$ of all visits by under $5 \mathrm{~s}$ across all

234 clusters. The visits in this cluster were characterised by a shorter waiting time than all of the other

235 clusters, at an average of 43.81 minutes. The rate of patients with PS1 status was $87 \%$, i.e. higher than

23611 of the other clusters, while the use of the fast-track (short) circuit was 3.89 times more frequent

237 than use of the long triage circuit.

238 Numerous clusters had health problems that were predominantly trauma-based, namely clusters 5, 7,

$2398,10,12,13,14$ and indirectly, clusters 1, 3, 6, 9. $28.61 \%$ of the ED visits resulted in diagnoses from

240 Chapter XIX, Injury, poisoning and certain other consequences of external causes. Furthermore, there

241 was a limited number of diagnosis blocks in most of them, ranging from 1 to 2 , with a high number of

242 individual diagnostic codes, ranging from 45 to 304 for clusters 5, 7, 8, 10, 11, 13 and 14.

243 The before-and-after analysis shows a significant overall decrease of 32.65 visits per week for the 14

244 clusters $(2.93 \%$, F-test, $\mathrm{p}=3.55 \mathrm{E}-02)$ and a specific decrease of 57.95 visits per week in 7 clusters

245 (13.59\%, F-test, p=1.92E-10). As illustrated by Figure 3 and described in Table 2, Clusters 3, 5, 7, 9,

$24610,13,14$, were associated with this decrease with significant downward trends (illustrated in). The

247 specific decrease corresponds to a loss of 0.083 visits per patient over a period of 2 years. The before-

248 and-after analysis also showed a significant (F-test, $p=6.20 \mathrm{E}-03$ ) increase of 17.44 visits per week

$249(10.27 \%)$ in cluster 1 and a non-significant (F-test, $\mathrm{p}=0.48)$ increase of 17.56 visits per week (13.19\%)

250 in cluster 4.

251 Structural analysis of the 6,199 visits without diagnostic codes showed a non-significant increase of

2522.37 visits per week ( $F$-test, $\mathrm{p}=0.64$ ). They went from an average of 58.18 visits per week in the

253 "before" period to 60.57 in the "after" period. More than two thirds (4266 visits, $68.82 \%$ ) of these 
visits involved patients who left without waiting for the medical examination. The other patients (1853 visits, $21.18 \%$ ) could not be diagnosed due to lack of information or to the nature of stay. visits per week before the opening of the USC, to $1139.29 \pm 51.83$ visits per week afterwards, with a significant linear trend (F-test, $\mathrm{p}=1.61 \mathrm{E}-06)$. Unscheduled care in the Department increased significantly by 328.12 visits per week $(14.75 \%$, F-test, $p=4.25 \mathrm{E}-04)$ during the study period.

260 Additional analysis of the national healthcare information database illustrated by Figure 4, showed that 261 in the first 6 months after the opening of the UCS, unscheduled care went from a baseline of $2622225.13 \pm 258.43$ visits to $2553.25 \pm 261.27$ visits per week. This increase was mainly due to the 263 opening of the UCS, where attendance was $189.5 \pm 62.54$ visits per week during this period. Using this 264 volume as reference, the ratio of the specific cluster decreases observed in the ED to the increase in the UCS was $30.58 \%$.

266 The multivariate analysis shows that the probability of belonging to one of the 7 clusters with a 267 significant reduction decreased after the opening of the UCS. As illustrated by Table 3 with an odds 268 ratio (OR) of $0.83(95 \% \mathrm{CI}[0.81,0.86])$, this corresponds to a reduction in these clusters after the 269 opening of the UCS. The ORs of the different variables indicate that the population concerned is less 270 subject to weekly readmissions (OR 0.65, (95\%CI $[0.61,0.68])$, more often males, with an OR of 0.70 $271(95 \% \mathrm{CI}[0.68,0.72])$ for female gender. This population also had a more moderate disease state, with 272 an OR of $1.23(95 \%$ CI $[1.18,1.27])$ for PS1 status, older age, with an OR of 1.41 (95\%CI $[1.77,1.97])$ 273 for the age category 75 years and older, and greater need for radiological examinations, with an OR of $2741.47(95 \% \mathrm{CI}[1.45,1.49])$.

\section{DISCUSSION}

276 Our results show a decrease in the probability of belonging to 7 clusters after the opening of 277 unscheduled care services (UCS). The reduction predominantly involved patient profiles linked to 278 trauma and trauma-related symptoms. This drop is in line with the type of patients managed by the 279 UCS in question. Our findings further show a non-significant increase in infectious diseases and a 
significant increase in general symptoms of chronic conditions. These increases partially compensate 281 the decrease in visits of the 7 clusters mentioned earlier. Temporal trends in patient profiles of these 2 282 clusters are mainly due to seasonal variations, notably during the winter periods of epidemic and 283 overcrowding of ED services, rather than representing a true trend related to the opening of UCS. 284 Consequently, the implementation of UCS is associated with a change in patient flow to the ED, but 285 the more pronounced increase in passage through the UCS, which was of greater magnitude than the 286 reduction in ED visits, suggests that the UCS may also have diverted the flow of patients that would 287 have been treated by appointment-based care otherwise.

288 Our study applied a novel method of analysing multimorbities by clustering the general population of 289 ED patients. To the best of our knowledge; and based on the review of Padros-Torres et al.[22], where 290 most studies focus on complex patient and chronic diseases [21-25], this is the first time that analysis 291 of multimorbidity patterns has been used to cluster healthcare visits in a temporal analysis, and in this specific population. With our novel method, we extend the usage of theses methods to a global 293 population with a low multimorbidity context and with a comprehensive clustering that was able to 294 classify the vast majority of ED visits (92.93\%).

295 Previous studies investigating the impact of UCS have reported substantial reductions in "avoidable" 296 ED visits, as well as cost reductions [11-15]. Using a questionnaire, Moe et al measured the impact of 297 an after-hours clinic in terms of avoided ED visits and cost savings, and found that $36.8 \%$ of patients 298 attending the after-hours clinic would otherwise have gone to the ED if the clinic had not been 299 available [11]. In their study investigating the use of convenient care clinics (CCCs) outside of typical 300 office hours, Patwardhan et al [13] found that among over 2.6 million encounters, in the absence of 301 CCCs, $4.5 \%$ of all patients would have gone to the ED for weekend and after-hours encounters and $3023.15 \%$ for weekday encounters during office hours, and respectively $29.39 \%$ and $27.34 \%$ would have 303 gone to an urgent care centre. In our study, the observed rate of $30.58 \%$ is similar to these literature 304 reports. In a before-and-after study of monthly ED visit frequency after implementation of an after305 hours clinic, Jones et al reported a mean of 49.28 fewer semiurgent patient visits per month to the ED 306 [15]. With an average reduction of 57.95 visits per week, corresponding to a reduction of $13.59 \%$ in 
the 7 clusters with significant decreases, and a reduction of $4.96 \%$ of all ED visits, our findings are in

308 the same range as these previous reports. The observed success can be explained by the large

309 proportion of "avoidable" visits among those attending the ED. These patients are often characterised

310 by low acuity and high vulnerability $[5,35,36]$, and re-directing them towards sites of care other than

311 the ED yields cost savings. One of the major obstacles to greater success of UCS is likely the

312 behaviour of patients, some of whom may prefer to go to the ED because they do not know that

313 alternatives exist, or because there is no financial incentive inciting them to try less costly care options

314 first [4, 37-40]. In this regard, information campaigns or the introduction of co-payment fees for ED

315 visits can be helpful in limiting "avoidable" ED attendance. However, unscheduled consultations

316 remain a weak link in the delivery of programmed healthcare, and are more difficult to manage. The

317 creation of care sites specifically for unscheduled care calls on public demand for such services that

318 can result in an increase of overall costs and new problems of saturation and overcrowding. As

319 improving access to primary care seems to be insufficient [41, 42], other solutions remain to be found

320 to limit social vulnerability and improve the general health of the population $[38,43]$.

321 Limits

322 The present study also has some limitations. Firstly, there is potential for selection bias in the 323 population of the city of Troyes. Nevertheless, this bias is minimized by previous reports in the 324 literature showing that our population is representative of the national population [31]. Secondly, the 325 choices made for our clustering approach with a block level representation of the diagnostic on a 326 global and non-stratified population also limits the accuracy of the clusters in terms of population 327 health problems. However, this approach achieves better statistical representativeness with a relevant 328 and coherent set of diseases cluster for the entire population. Indeed, these choices obviate the need for 329 a high number of lower quality clusters with pattern redundancies that would render the results 330 difficult to interpret and read. Thirdly, in this study, there was no control group unaffected by the 331 opening of UCS. The conditions of access to healthcare data from other Departments, and the specificity of the local context precluded us from using a design that might limit this bias. 
335 In this study, we propose an original and reliable method for assessing changes in patient flow through

336 different healthcare delivery services that can be extrapolated to several contexts. It requires only the

337 existence of a system for labelling diagnoses, so that their co-occurrence can be measured in the

338 patients' records. It has been shown to be efficacious when patients are characterised according to

339 hierarchical codes such as the ICD10 diagnostic system, and can also be successfully applied to study

340 temporal trends in relation to a specific event, even in the absence of a control group. This

341 methodological approach is fully in line with current thinking on public health policy, aiming to

342 reorganise the relationships between primary care and emergency departments, with a view to

343 improving the functioning of EDs by boosting the offer of unscheduled and/or non-urgent care. The

344 implementation of new unscheduled care services was accompanied by a decrease in ED visits among

345 multiple patient profiles, in line with the type of patients cared for by the new services. This new

346 distribution of healthcare delivery therefore had a concrete impact and helped to optimise patient flow

347 through the different sites of care. 
358 LIST OF ABBREVIATIONS

359 ED: Emergency Department

360 HAC: Hierarchical Agglomerative Clustering

361 ICD: International Classification of Diseases

362 RR: Relative Risk

363 MR: Membership Ratio

364 UCS: Unscheduled Care Services

365

366

367

368

369

370

371

372

373

374

375

376

377

378 


\section{DECLARATIONS}

\section{Ethics approval and consent to participate}

381 This study was performed in compliance with national legislation regarding epidemiological studies 382 (declaration $\mathrm{N}^{\circ} 2203674 \mathrm{v} 0$, dated 24/07/2018). Since the study was wholly observational and used 383 only anonymized data, neither ethics approval nor a specific written informed consent from 384 participants was required in France for this retrospective database study. In accordance with French 385 ethical directives, the requirement for written informed consent was waived because the study was 386 strictly observational, and all data were blinded. (ref : French Public Health Code. Article R. 1121-2. 387 [http://www.legifrance.gouv.fr] ). According to the French Public Health Code, this research not 388 needed an ethical committee (ref :French Public Health Code. Article R. 1121-2.

389 [http://www.legifrance.gouv.fr]). . The study is conducted according to the legal representant of 390 medical information: it was declared with the national registry of health research under the number $391 \quad \mathrm{~N}^{\circ} 1113130319$. Patients were informed that the study was being carried out through the hospital's 392 registry of ongoing studies.

\section{Consent for publication}

394 Not applicable

\section{Availability of data and materials}

396 The main dataset containing the patient's exact stay with arrival date, ID number, stay number, age,

397 gender, diagnoses, and other information described in the methods section cannot be made publicly 398 available due to its confidential nature. Access is restricted by law to researchers that have complied 399 with national legislation regarding epidemiological studies. It can be made available from the 400 corresponding author on reasonable and legal request.

401 All analyses and data management were performed using $\mathrm{R}$ version 3.5.2. The code of the clustering 402 method, with intermediate tables for testing, is available upon request and requires for execution the 403 open software RStudio with 3 libraries: tidyverse, lubridate, reshape2. 


\section{Competing interests}

405 None declared: The author(s) declare no conflict of interests.

\section{$406 \quad$ Funding}

407 None. No financial relationships with any organizations that might have an interest

408 in or have influenced the submitted the manuscript.

\section{Author's contributions}

410 JC, DL, AW, FMC, FY and SS designed the study. SS, DL, TM, GS contributed to the acquisition of 411 data. JC conducted the statistical analysis. JC, TM, GS, HQ, AD, DL and SS contributed to drafting 412 the article or revising it critically for important intellectual content. All authors read and approved the 413 final manuscript.

\section{Acknowledgements}

415 We would like to thank Fiona Ecarnot for her contribution in traduction.

\section{Authors' information}

$417{ }^{1}$ Université Technologique de Troyes, Institut Charles Delaunay, Troyes, F-10000, France

$418{ }^{2}$ Centre Hospitalier de Troyes, Health Services and Performance Research Lab, Troyes, F-10000, 419 France

$420{ }^{3}$ Centre Hospitalier de Troyes, Emergency Department, Troyes, F-10000, France

$421 \quad{ }^{4}$ Etablissement Aubois des Soins Immédiats, Troyes, F-10000, France

$422{ }^{5}$ Hospices Civils de Lyon, Health Data Department, Lyon, F-69003, France

$423{ }^{6}$ Université Claude Bernard Lyon 1, Health Services and Performance Research Lab (HESPER 424 EA7425), F-69008 Lyon, France

$425{ }^{7}$ Brigham and Women's Hospital, Harvard Medical School, Center for Surgery and Public Health, 426 Boston, MA, USA 


\section{REFERENCES}

433 1. DREES. France. Ministère du travail, de l'emploi et de la santé. Direction de la recherche, des

434 études, de l'évaluation et des statistiques. Le panorama des établissements de santé : édition 2017.

435 2017. https://drees.solidarites-sante.gouv.fr/IMG/pdf/28-2.pdf.

436 2. Morley C, Unwin M, Peterson GM, Stankovich J, Kinsman L. Emergency department crowding: A 437 systematic review of causes, consequences and solutions. PLoS One. 2018;13:e0203316. 438 doi:10.1371/journal.pone.0203316.

439 3. Han JH, Zhou C, France DJ, Zhong S, Jones I, Storrow AB, et al. The Effect of Emergency

440 Department Expansion on Emergency Department Overcrowding. Acad Emerg Med. 2007.

441 4. Capp R, Camp-Binford M, Sobolewski S, Bulmer S, Kelley L. Do Adult Medicaid Enrollees Prefer 442 Going to Their Primary Care Provider's Clinic Rather Than Emergency Department (ED) for Low 443 Acuity Conditions? Med Care. 2015;53:530-3. doi:10.1097/mlr.0000000000000364.

444 5. Naouri D, Ranchon G, Vuagnat A, Schmidt J, El Khoury C, Yordanov Y. Factors associated with 445 inappropriate use of emergency departments: findings from a cross-sectional national study in France. 446 BMJ Qual \&amp;amp; Saf. 2019;:bmjqs-2019-009396. doi:10.1136/bmjqs-2019-009396.

447 6. LaCalle E, Rabin E. Frequent users of emergency departments: the myths, the data, and the policy 448 implications. Ann Emerg Med. 2010;56:42-8. doi:10.1016/j.annemergmed.2010.01.032.

449 7. Durand AC, Palazzolo S, Tanti-Hardouin N, Gerbeaux P, Sambuc R, Gentile S. Nonurgent patients 450 in emergency departments: rational or irresponsible consumers? Perceptions of professionals and 
452 8. Jarvis PRE. Improving emergency department patient flow. Clin Exp Emerg Med. 2016;3:63-8.

453 doi:10.15441/ceem.16.127.

454 9. Chrusciel J, Fontaine X, Devillard A, Cordonnier A, Kanagaratnam L, Laplanche D, et al. Impact of 455 the implementation of a fast-Track on emergency department length of stay and quality of care 456 indicators in the Champagne-Ardenne region: A before-After study. BMJ Open. 2019.

457 10. Ablard S, O’Keeffe C, Ramlakhan S, Mason SM. Primary care services co-located with 458 Emergency Departments across a UK region: early views on their development. Emerg Med J. $459 \quad 2017 ; 34: 672-6$.

460 11. Moe J, Oland R, Moe G. Impact of a Primary Care After-Hours Clinic on Avoidable Emergency 461 Department Visits and Costs. Heal Q. 2019;22:42-7. doi:10.12927/hcq.2019.25837.

462 12. Thakkar AB, Chandrashekar P, Wang W, Blanchfield BB. Impact of a Student-Run Clinic on 463 Emergency Department Utilization. Fam Med. 2019;51:420-3. doi:10.22454/FamMed.2019.477798.

464 13. Patwardhan A, Davis J, Murphy P, Ryan SF. After-hours Access of Convenient Care Clinics and 465 Cost Savings Associated With Avoidance of Higher-Cost Sites of Care. J Prim Care Community Heal. $466 \quad$ 2012;3:243-5. doi:10.1177/2150131911436251.

467 14. DeVries A, Li C-H, Oza M. Strategies to Reduce Nonurgent Emergency Department Use:

468 Experience of a Northern Virginia Employer Group. Med Care. 2013;51:224-30.

469 doi:10.1097/MLR.0b013e3182726b83.

470 15. Jones D, Carroll L, Frank L. After-hours care in suburban Canada: influencing emergency 471 department utilization. J Prim Care Community Heal. 2011;2:250-4. doi:10.1177/2150131911408431.

472 16. Granger B. « Ma santé 2022 » un plan ambitieux, des moyens limités. Debat. 2019.

473 17. Gay B, Duhamel S. La situation des soins de santé primaires en France. Médecine. 2019;15:34-7.

474 18. Soler G, Bouleux G, Marcon E, Cantais A, Pillet S, Mory O. Emergency Department Admissions 
Overflow Modeling by a Clustering of Time Evolving Clinical Diagnoses. In: 2018 IEEE 14th International Conference on Automation Science and Engineering (CASE). IEEE; 2018. p. 365-70. doi:10.1109/COASE.2018.8560585.

19. Afilal M, Yalaoui F, Dugardin F, Amodeo L, Laplanche D, Blua P. Emergency department flow: A new practical patients classification and forecasting daily attendance. IFAC-PapersOnLine. 2016;49:721-6. doi:https://doi.org/10.1016/j.ifacol.2016.07.859.

20. Everitt BS, Landau S, Leese M, Stahl D. Cluster Analysis. John Wiley \& Sons; 2011. https://books.google.fr/books?id=w3bE1kqd-48C.

21. Tangianu F, Gnerre P, Colombo F, Frediani R, Pinna G, Berti F, et al. Could clustering of comorbidities be useful for better defining the internal medicine patients' complexity? Ital J Med. 2018.

22. Prados-Torres A, Calderón-Larrañaga A, Hancco-Saavedra J, Poblador-Plou B, Van Den Akker M. Multimorbidity patterns: A systematic review. Journal of Clinical Epidemiology. 2014.

23. Violán C, Roso-Llorach A, Foguet-Boreu Q, Guisado-Clavero M, Pons-Vigués M, Pujol-Ribera E, et al. Multimorbidity patterns with K-means nonhierarchical cluster analysis. BMC Fam Pract. 2018.

24. Violán C, Foguet-Boreu Q, Fernández-Bertolín S, Guisado-Clavero M, Cabrera-Bean M, Formiga F, et al. Soft clustering using real-world data for the identification of multimorbidity patterns in an elderly population: Cross-sectional study in a Mediterranean population. BMJ Open. 2019.

25. Schäfer I, von Leitner E-C, Schön G, Koller D, Hansen H, Kolonko T, et al. Multimorbidity Patterns in the Elderly: A New Approach of Disease Clustering Identifies Complex Interrelations between Chronic Conditions. PLoS One. 2010;5:e15941. doi:10.1371/journal.pone.0015941. 26. Vetrano DL, Roso-Llorach A, Fernández S, Guisado-Clavero M, Violán C, Onder G, et al. Twelve-year clinical trajectories of multimorbidity in a population of older adults. Nat Commun. 2020;11:3223. doi:10.1038/s41467-020-16780-x.

27. Khanolkar AR, Patalay P. Clustering \& trajectories of multimorbidity across the lifecourse: a 70 
year birth cohort study. Eur J Public Health. 2019.

501 28. Travers DA, Haas SW, Waller AE, Tintinalli JE. Diagnosis clusters for emergency medicine. Acad 502 Emerg Med Off J Soc Acad Emerg Med. 2003;10:1337-44.

503 http://www.ncbi.nlm.nih.gov/pubmed/14644786.

504 29. Gandhi SO, Sabik L. Emergency department visit classification using the NYU algorithm. Am J 505 Manag Care. 2014;20:315-20. https://www.ncbi.nlm.nih.gov/pubmed/24884862.

506 30. Hansen-Turton T, Ryan S, Miller K, Counts M, Nash DB. Convenient care clinics: The future of 507 accessible health care. Dis Manag. 2007.

508 31. Naouri D, Khoury C E1, Vincent-Cassy C, Vuagnat A, Schmidt J, Yordanov Y. The French 509 emergency national survey: A description of emergency departments and patients in France. PLoS 510 One. 2018.

511 32. Cornell JE, Pugh JA, Williams, Jr JW, Kazis L, Lee AFS, Parchman ML, et al. Multimorbidity 512 Clusters: Clustering Binary Data From Multimorbidity Clusters: Clustering Binary Data From a Large 513 Administrative Medical Database. Appl Multivar Res. 2009;12:163.

514 33. Globerson A, Chechik G, Pereira F, Tishby N. Euclidean embedding of co-occurrence data. J 515 Mach Learn Res. 2007.

516 34. Bozdogan H. Akaike’s Information Criterion and Recent Developments in Information

517 Complexity. J Math Psychol. 2000;44:62-91. doi:https://doi.org/10.1006/jmps.1999.1277.

518 35. Hsia RY, Niedzwiecki M. Avoidable emergency department visits: A starting point. Int J Qual 519 Heal Care. 2017;29:642-5.

520 36. Leporatti L, Ameri M, Trinchero C, Orcamo P, Montefiori M. Targeting frequent users of 521 emergency departments: Prominent risk factors and policy implications. Health Policy (New York). $522 \quad 2016 ; 120: 462-70$.

523 37. Capp R, Kelley L, Ellis P, Carmona J, Lofton A, Cobbs-Lomax D, et al. Reasons for Frequent 524 Emergency Department Use by Medicaid Enrollees: A Qualitative Study. Acad Emerg Med. 2016;23. 

physician-provided patient education about alternative care venues. Am J Manag Care. 2018.

39. Petrou P, Ingleby D. Co-payments for emergency department visits: a quasi-experimental study. Public Health. 2019;169:50-8. doi:10.1016/j.puhe.2018.12.014.

40. Baum Z, Simmons MR, Guardiola JH, Smith C, Carrasco L, Ha J, et al. Potential impact of co530 payment at point of care to influence emergency department utilization. PeerJ. 2016.

531 41. Hefner JL, Wexler R, McAlearney AS. Primary Care Access Barriers as Reported by Nonurgent 532 Emergency Department Users: Implications for the US Primary Care Infrastructure. Am J Med Qual. 5332015.

534 42. Oterino De La Fuente D, Baños Pino JF, Blanco VF, Álvarez AR. Does better access to primary 535 care reduce utilization of hospital accident and emergency departments? A time-series analysis. Eur J 536 Public Health. 2007. 
548

549

550

551

552 


\section{Tables}

Table 1 - Characteristics of the 14 clusters

\begin{tabular}{|c|c|c|c|c|c|c|c|}
\hline Cluster name & $\begin{array}{l}1: \text { General } \\
\text { symptoms of } \\
\text { chronic } \\
\text { conditions }\end{array}$ & $\begin{array}{l}2 \text { : Digestive } \\
\text { disorders, } \\
\text { pregnancy, } \\
\text { menstruation }\end{array}$ & $\begin{array}{l}3 \text { : General } \\
\text { symptoms and } \\
\text { mental } \\
\text { disorders }\end{array}$ & $\begin{array}{l}4: \text { Infectious } \\
\text { diseases }\end{array}$ & $\begin{array}{l}5: \text { Head } \\
\text { Trauma }\end{array}$ & $\begin{array}{l}6: \text { Mental } \\
\text { disorders and } \\
\text { at-risk } \\
\text { behaviours }\end{array}$ & $\begin{array}{l}7: \text { Hand and } \\
\text { Wrist Trauma }\end{array}$ \\
\hline Population : n(\%) & $14151(19 \%)$ & $13982(19 \%)$ & $12202(17 \%)$ & $11150(15 \%)$ & $10318(14 \%)$ & $9535(13 \%)$ & $6293(9 \%)$ \\
\hline Age, mean \pm standard deviation & $58.44(+-26.98)$ & $36.51(+-23.11)$ & $49.51(+-28.88)$ & $20.77(+-24.78)$ & $31.00(+-25.81)$ & $38.60(+-22.55)$ & $32.21(+-20.95)$ \\
\hline Females, n(\%) & $8345(46 \%)$ & $12936(69 \%)$ & $7560(53 \%)$ & $7036(49 \%)$ & $4810(43 \%)$ & $6080(50 \%)$ & $2597(38 \%)$ \\
\hline Visits, n(\%) & $18020(16 \%)$ & $18617(16 \%)$ & $14241(12 \%)$ & $14271(12 \%)$ & $11220(10 \%)$ & $12075(11 \%)$ & $6755(6 \%)$ \\
\hline Number of visits per patient & 1.27 & 1.33 & 1.17 & 1.28 & 1.09 & 1.27 & 1.07 \\
\hline $\begin{array}{l}\text { Waiting time, minutes; median (Q1- } \\
\text { Q3) }\end{array}$ & $\begin{array}{l}47.68 \\
(21.75-99.62)\end{array}$ & $\begin{array}{l}59.30 \\
(29.22-111.06)\end{array}$ & $\begin{array}{l}57.65 \\
(27.25-117.53)\end{array}$ & $\begin{array}{l}43.81 \\
(22.97-77.12)\end{array}$ & $\begin{array}{l}59.27 \\
(30.25-105.23)\end{array}$ & $\begin{array}{l}44.06 \\
(18.10-93.90)\end{array}$ & $\begin{array}{l}58.83 \\
(30.90-105.27)\end{array}$ \\
\hline $\begin{array}{l}\text { Duration of management, minutes; } \\
\text { median }(\mathrm{Q} 1-\mathrm{Q} 3)\end{array}$ & $\begin{array}{l}261.33 \\
(144.43-403.46)\end{array}$ & $\begin{array}{l}160.18 \\
(48.00-313.63)\end{array}$ & $\begin{array}{l}233.90 \\
(101.99-379.34)\end{array}$ & $\begin{array}{l}64.69 \\
(31.25-153.80)\end{array}$ & $\begin{array}{l}70.17 \\
(39.02-130.03)\end{array}$ & $\begin{array}{l}137.10 \\
(61.12-280.97)\end{array}$ & $\begin{array}{l}70.65 \\
(43.38-113.80)\end{array}$ \\
\hline $\begin{array}{l}\text { Number of medications, } \\
\text { mean } \pm \text { standard deviation }\end{array}$ & $4.58(+-5.63)$ & $2.58(+-3.90)$ & $3.25(+-4.44)$ & $1.32(+-3.09)$ & $1.06(+-2.18)$ & $1.66(+-2.93)$ & $1.17(+-1.73)$ \\
\hline $\begin{array}{l}\text { Number of biology exams, } \\
\text { mean } \pm \text { standard deviation }\end{array}$ & $2.79(+-2.20)$ & $1.91(+-1.96)$ & $2.15(+-2.17)$ & $0.73(+-1.49)$ & $0.19(+-0.79)$ & $1.19(+-1.90)$ & $0.11(+-0.49)$ \\
\hline $\begin{array}{l}\text { Number of radiological exams, } \\
\text { mean } \pm \text { standard deviation }\end{array}$ & $1.48(+-1.18)$ & $0.54(+-0.87)$ & $1.35(+-1.33)$ & $0.31(+-0.71)$ & $0.96(+-1.13)$ & $0.85(+-1.16)$ & $0.98(+-0.94)$ \\
\hline Number of blocks of diagnoses & 42 & 28 & 8 & 20 & 1 & 15 & 1 \\
\hline Number of ICD10 diagnostic codes & 513 & 482 & 157 & 284 & 105 & 330 & 52 \\
\hline Ratio of short circuit to long circuit & 0.36 & 1.26 & 0.61 & 3.89 & 14.76 & 1.91 & 93.55 \\
\hline Patients in PS1 status, n(\%) & $9636(53 \%)$ & $14364(77 \%)$ & $9211(65 \%)$ & $12429(87 \%)$ & $10479(93 \%)$ & $8705(72 \%)$ & $6294(93 \%)$ \\
\hline Number admitted to hospital, n(\%) & $7873(44 \%)$ & $3918(21 \%)$ & $4764(33 \%)$ & $1748(12 \%)$ & $626(6 \%)$ & $2678(22 \%)$ & $368(5 \%)$ \\
\hline Rate of readmission within 7 days (\%) & $5.26 \%$ & $9.29 \%$ & $5.48 \%$ & $6.45 \%$ & $3.39 \%$ & $6.72 \%$ & $3.88 \%$ \\
\hline
\end{tabular}


Table 1 (continued) - Characteristics of the 14 clusters

\begin{tabular}{|c|c|c|c|c|c|c|c|}
\hline Cluster name & $\begin{array}{l}8 \text { : Spine } \\
\text { disorders }\end{array}$ & $\begin{array}{l}9: \\
\text { Occulomotor } \\
\text { disorders }\end{array}$ & $\begin{array}{l}10 \text { : Lower } \\
\text { limb trauma } \\
\text { and hemopathy }\end{array}$ & $\begin{array}{l}\text { 11: } \\
\text { Arthropathies }\end{array}$ & $\begin{array}{l}12 \text { : Chest } \\
\text { trauma and at- } \\
\text { risk behaviours }\end{array}$ & $\begin{array}{l}13: \text { Shoulder } \\
\text { and arm } \\
\text { trauma }\end{array}$ & $\begin{array}{l}14 \text { : Cutaneous } \\
\text { infections and } \\
\text { wounds }\end{array}$ \\
\hline Population : n(\%) & $3455(5 \%)$ & $3038(4 \%)$ & $3007(4 \%)$ & $2601(4 \%)$ & $2084(3 \%)$ & $1822(3 \%)$ & $1799(2 \%)$ \\
\hline Age, mean \pm standard deviation & $45.51(+-22.58)$ & $39.44(+-23.83)$ & $36.02(+-23.82)$ & $45.81(+-25.40)$ & $45.93(+-23.60)$ & $40.97(+-26.87)$ & $33.21(+-21.12)$ \\
\hline Females, n(\%) & $2060(55 \%)$ & $1254(39 \%)$ & $1381(43 \%)$ & $1304(48 \%)$ & $1129(47 \%)$ & $834(43 \%)$ & $857(44 \%)$ \\
\hline Visits, $\mathbf{n}(\%)$ & $3756(3 \%)$ & $3226(3 \%)$ & $3201(3 \%)$ & $2738(2 \%)$ & $2386(2 \%)$ & $1919(2 \%)$ & $1966(2 \%)$ \\
\hline Number of visits per patient & 1.09 & 1.06 & 1.06 & 1.05 & 1.14 & 1.05 & 1.09 \\
\hline $\begin{array}{l}\text { Waiting time, minutes; median (Q1- } \\
\text { Q3) }\end{array}$ & $\begin{array}{l}62.00 \\
(32.06-111.47)\end{array}$ & $\begin{array}{l}55.23 \\
(29.30-94.68)\end{array}$ & $\begin{array}{l}59.78 \\
(31.32-107.80)\end{array}$ & $\begin{array}{l}60.62 \\
(32.57-110.72)\end{array}$ & $\begin{array}{l}54.35 \\
(26.26-99.12)\end{array}$ & $\begin{array}{l}48.65 \\
(21.92-92.75)\end{array}$ & $\begin{array}{l}58.58 \\
(32.33-103.68)\end{array}$ \\
\hline $\begin{array}{l}\text { Duration of management, minutes; } \\
\text { median (Q1-Q3) }\end{array}$ & $\begin{array}{l}125.00 \\
(55.37-275.53)\end{array}$ & $\begin{array}{l}44.13 \\
(23.28-90.58)\end{array}$ & $\begin{array}{l}89.43 \\
(53.47-146.97)\end{array}$ & $\begin{array}{l}94.52 \\
(44.72-222.18)\end{array}$ & $\begin{array}{l}105.10 \\
(44.50-252.83)\end{array}$ & $\begin{array}{l}104.36 \\
(61.55-177.15)\end{array}$ & $\begin{array}{l}64.10 \\
(31.37-132.08)\end{array}$ \\
\hline $\begin{array}{l}\text { Number of medications, } \\
\text { mean } \pm \text { standard deviation }\end{array}$ & $2.56(+-3.89)$ & $0.66(+-1.78)$ & $1.51(+-2.62)$ & $2.02(+-3.81)$ & $2.08(+-3.74)$ & $2.21(+-3.22)$ & $1.32(+-2.67)$ \\
\hline $\begin{array}{l}\text { Number of biology exams, } \\
\text { mean } \pm \text { standard deviation }\end{array}$ & $0.76(+-1.34)$ & $0.20(+-0.92)$ & $0.35(+-1.04)$ & $0.96(+-1.85)$ & $1.09(+-1.76)$ & $0.40(+-0.99)$ & $0.59(+-1.31)$ \\
\hline $\begin{array}{l}\text { Number of radiological exams, } \\
\text { mean } \pm \text { standard deviation }\end{array}$ & $1.12(+-1.42)$ & $0.18(+-0.56)$ & $1.25(+-1.20)$ & $1.18(+-1.37)$ & $1.26(+-1.43)$ & $2.03(+-1.52)$ & $0.23(+-0.56)$ \\
\hline Number of blocks of diagnoses & 2 & 11 & 2 & 2 & 9 & 1 & 8 \\
\hline Number of ICD10 diagnostic codes & 118 & 94 & 45 & 304 & 113 & 30 & 123 \\
\hline Ratio of short circuit to long circuit & 2.70 & 13.44 & 17.60 & 3.45 & 2.49 & 18.14 & 8.06 \\
\hline Patients in PS1 status & $3034(81 \%)$ & $3053(95 \%)$ & $2767(86 \%)$ & $2246(82 \%)$ & $1900(80 \%)$ & $1594(83 \%)$ & $1583(81 \%)$ \\
\hline Number admitted to hospital, n(\%) & $670(18 \%)$ & $148(5 \%)$ & $413(13 \%)$ & $466(17 \%)$ & $441(18 \%)$ & $301(16 \%)$ & $360(18 \%)$ \\
\hline Rate of readmission within 7 days (\%) & $4.77 \%$ & $3.84 \%$ & $4.90 \%$ & $4.57 \%$ & $8.38 \%$ & $4.48 \%$ & $7.48 \%$ \\
\hline
\end{tabular}


Table 2 - Before-After Analysis of the weekly visits for each cluster

\begin{tabular}{|c|c|c|c|c|}
\hline Cluster name & $\begin{array}{l}\text { Before UCS } \\
\text { opened (mean } \pm \\
\text { SD) }\end{array}$ & $\begin{array}{l}\text { After UCS } \\
\text { opened (mean } \\
\pm \text { SD) }\end{array}$ & Difference (\%) & $\mathbf{P} *$ \\
\hline $\begin{array}{l}1 \text { : General symptoms of } \\
\text { chronic conditions }\end{array}$ & $169.74 \pm 25.48$ & $187.18 \pm 23.49$ & $17.44(10.28 \%)$ & $6.20 \mathrm{E}-03$ \\
\hline $\begin{array}{l}2 \text { : Digestive disorders, } \\
\text { pregnancy, menstruation }\end{array}$ & $181.50 \pm 14.22$ & $175.68 \pm 14.22$ & $-5.82(-3.21 \%)$ & $6.63 \mathrm{E}-01$ \\
\hline $\begin{array}{l}3 \text { : General symptoms and } \\
\text { mental disorders }\end{array}$ & $140.99 \pm 14.84$ & $129.32 \pm 15.06$ & $-11.67(-8.27 \%)$ & $5.27 \mathrm{E}-05$ \\
\hline 4 : Infectious diseases & $133.12 \pm 39.93$ & $150.68 \pm 31.75$ & $17.56(13.19 \%)$ & 4.82E-01 \\
\hline 5 : Head Trauma & $113.87 \pm 16.76$ & $92.89 \pm 12.89$ & $-20.98(-18.42 \%)$ & $2.33 \mathrm{E}-06$ \\
\hline $\begin{array}{l}6: \text { Mental disorders and } \\
\text { at-risk behaviours }\end{array}$ & $118.41 \pm 17.48$ & $112.14 \pm 16.37$ & $-6.27(-5.29 \%)$ & $2.37 \mathrm{E}-01$ \\
\hline $\begin{array}{l}7 \text { : Hand and Wrist } \\
\text { Trauma }\end{array}$ & $68.04 \pm 11.25$ & $57.36 \pm 8.68$ & $-10.68(-15.70 \%)$ & $3.02 \mathrm{E}-03$ \\
\hline 8 : Spine disorders & $35.79 \pm 6.65$ & $37.75 \pm 5.34$ & $1.96(5.48 \%)$ & $1.66 \mathrm{E}-01$ \\
\hline 9 : Occulomotor disorders & $32.25 \pm 6.00$ & $28.00 \pm 5.93$ & $-4.25(-13.18 \%)$ & $1.29 \mathrm{E}-02$ \\
\hline $\begin{array}{l}10: \text { Lower limb trauma } \\
\text { and hemopathy }\end{array}$ & $32.43 \pm 7.95$ & $26.75 \pm 6.60$ & $-5.68(-17.53 \%)$ & $1.22 \mathrm{E}-03$ \\
\hline 11 : Arthropathies & $26.95 \pm 5.64$ & $25.43 \pm 6.13$ & $-1.52(-5.64 \%)$ & $8.85 \mathrm{E}-01$ \\
\hline $\begin{array}{l}12 \text { : Chest trauma and at- } \\
\text { risk behaviours }\end{array}$ & $22.66 \pm 5.21$ & $24.61 \pm 5.49$ & $1.95(8.60 \%)$ & $7.53 \mathrm{E}-02$ \\
\hline $\begin{array}{l}13: \text { Shoulder and arm } \\
\text { trauma }\end{array}$ & $19.47 \pm 4.45$ & $16.07 \pm 4.58$ & $-3.40(-17.47 \%)$ & $4.60 \mathrm{E}-03$ \\
\hline $\begin{array}{l}14: \text { Cutaneous infections } \\
\text { and wounds }\end{array}$ & $19.33 \pm 5.29$ & $18.04 \pm 3.76$ & $-1.29(-6.69 \%)$ & $1.19 \mathrm{E}-02$ \\
\hline Total & $1108.66 \pm 72.71$ & $\begin{array}{l}1076.18 \pm \\
49.76\end{array}$ & $-32.48(-2.93 \%)$ & $3.55 \mathrm{E}-02$ \\
\hline Total for negative trends & $425.74 \pm 34.94$ & $368.04 \pm 27.84$ & $-57.70(-13.55 \%)$ & $1.92 \mathrm{E}-10$ \\
\hline
\end{tabular}

For each series, the linear trend of the 2-year study period has been tested using Fisher's F test and resulting in a p-value. - SD : Standard deviation ; * Fisher test on linear trend (F test) 
Table 3 - Logistic regression model showing the factors associated with the probability of belonging to decreasing clusters

\begin{tabular}{|c|c|c|c|}
\hline Variable & $\mathrm{OR}^{*}$ & $95 \% \mathrm{CI} *$ & $\mathbf{p} * * *$ \\
\hline "After" period (reference: Before) & 0.83 & {$[0.81,0.86]$} & $1.57 \mathrm{E}-38$ \\
\hline Readmission within one week & 0.65 & {$[0.61,0.68]$} & $9.02 \mathrm{E}-57$ \\
\hline Female gender & 0.70 & {$[0.68,0.72]$} & $1.00 \mathrm{E}-177$ \\
\hline PS1 status & 1.23 & {$[1.18,1.27]$} & $0.00 \mathrm{E}+00$ \\
\hline Short circuit through ED & 2.25 & {$[2.17,2.34]$} & $0.00 \mathrm{E}+00$ \\
\hline \multicolumn{4}{|l|}{ Age category (Reference: $25-50$ years) } \\
\hline 0 - 10 years & 0.75 & {$[0.72,0.78]$} & $0.00 \mathrm{E}+00$ \\
\hline $10-25$ years & 1.18 & {$[1.14,1.22]$} & $0.00 \mathrm{E}+00$ \\
\hline 25 - 50 years & - & - & - \\
\hline 50 - 75 years & 1.20 & {$[1.16,1.25]$} & $0.00 \mathrm{E}+00$ \\
\hline 75 years and over & 1.41 & {$[1.35,1.48]$} & $0.00 \mathrm{E}+00$ \\
\hline Number of biological exams (per additional exam) & 0.82 & {$[0.81,0.83]$} & $2.03 \mathrm{E}-188$ \\
\hline Number of radiological exams (per additional exam) & 1.47 & {$[1.45,1.49]$} & $0.00 \mathrm{E}+00$ \\
\hline Waiting time (per additional hour) & 1.00 & {$[1.00,1.00]$} & $6.25 \mathrm{E}-47$ \\
\hline Duration of management (per additional hour) & 1.00 & {$[1.00,1.00]$} & 5.00E-09 \\
\hline \multicolumn{4}{|l|}{$\begin{array}{l}* \text { OR: Odd Ratio } \\
* * \text { CI: Confidence Interval } \\
* * * \text { Wald test (z-test) } \\
\text { AUC }=0.7 \\
\text { Hosmer-Lemeshow test }: \mathrm{X}^{2}=1584.6, \mathrm{p} \text {-value }<2.2 \mathrm{e}-16\end{array}$} \\
\hline
\end{tabular}




\section{Figure legends}

\section{Figure 1 - Visit selection flow chart from the RESURGENCES database}

Figure 2 - Distribution of blocks of diagnoses in the 14 clusters - Each cluster is represented by a unique colour. The volume of each area is proportional to the number of patients affected by the given block of diagnoses during the study period. The label of each block can be found at: https://www.icd10data.com/ICD10CM/Codes or in Supplementary Data Table S3 - Additional File 1

Figure 3 - Trends in clusters before and after the opening of UCS - The numbers of weekly admissions are represented with boxplots where the middle line indicates the median, the boxes delimit the quartiles. The upper and lower whisker extends from the hinge to the largest and smallest (resp.) value no further than $1.5 *$ IQR from the hinge. (where IQR is the inter-quartile range, or distance between the first and third quartiles).

\section{Figure 4 - Trends in unscheduled care in the Aube Department, December 2015 - December} 2019 - The numbers of weekly admissions is represented using lines for each type of unscheduled care surrounding the ED of Troyes. Ambulatory care is all the unscheduled consultations performed for the most part by general practitioners and nurses in the Aube territory via the SOS Médecin association and the Permanence Des Soins Ambulatoires (PDSA) registred in the Système Nationale des Données de Santé (SNDS, the national health information database).

\section{Additional File 1 content}

Supplementary Methods S1 - The detailed method used to cluster multimorbidity patterns is presented. The method is also compared to the literature.

\section{Supplementary Table S2 - Diagnostic content and quality indicators of the 14 clusters -}

Clustering result of the method presented in Supplementary Methods S1 with the data presented in the present Methods section with detailed information on the cluster, their content, and their quality.

Supplementary Data Table S3 - Labels of the ICD10 Blocks - Content of each block from the International Classification $10^{\text {th }}$ revision 
Figures

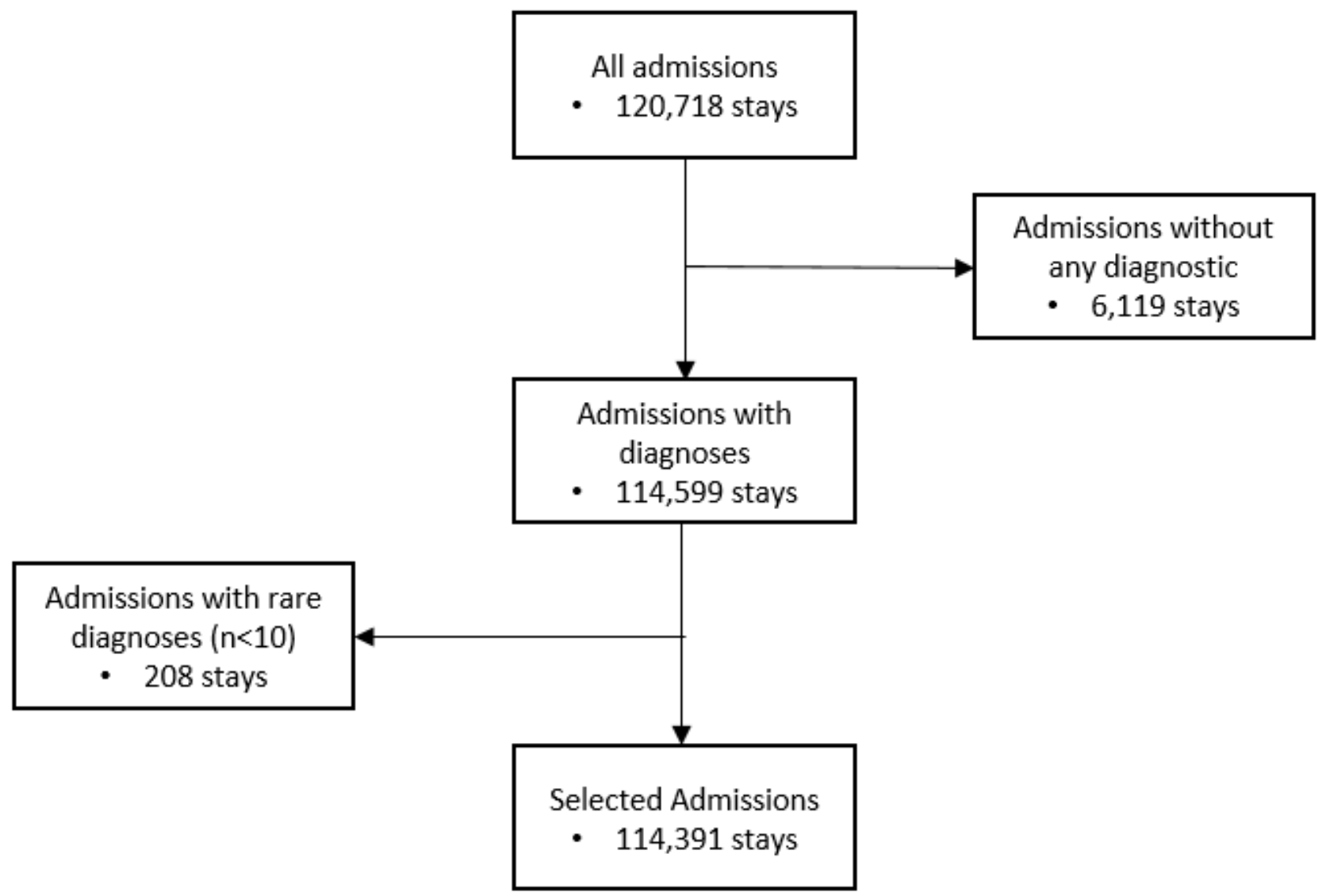

Figure 1

Visit selection flow chart from the RESURGENCES database 
Count of patients per cluster and block of diagnoses

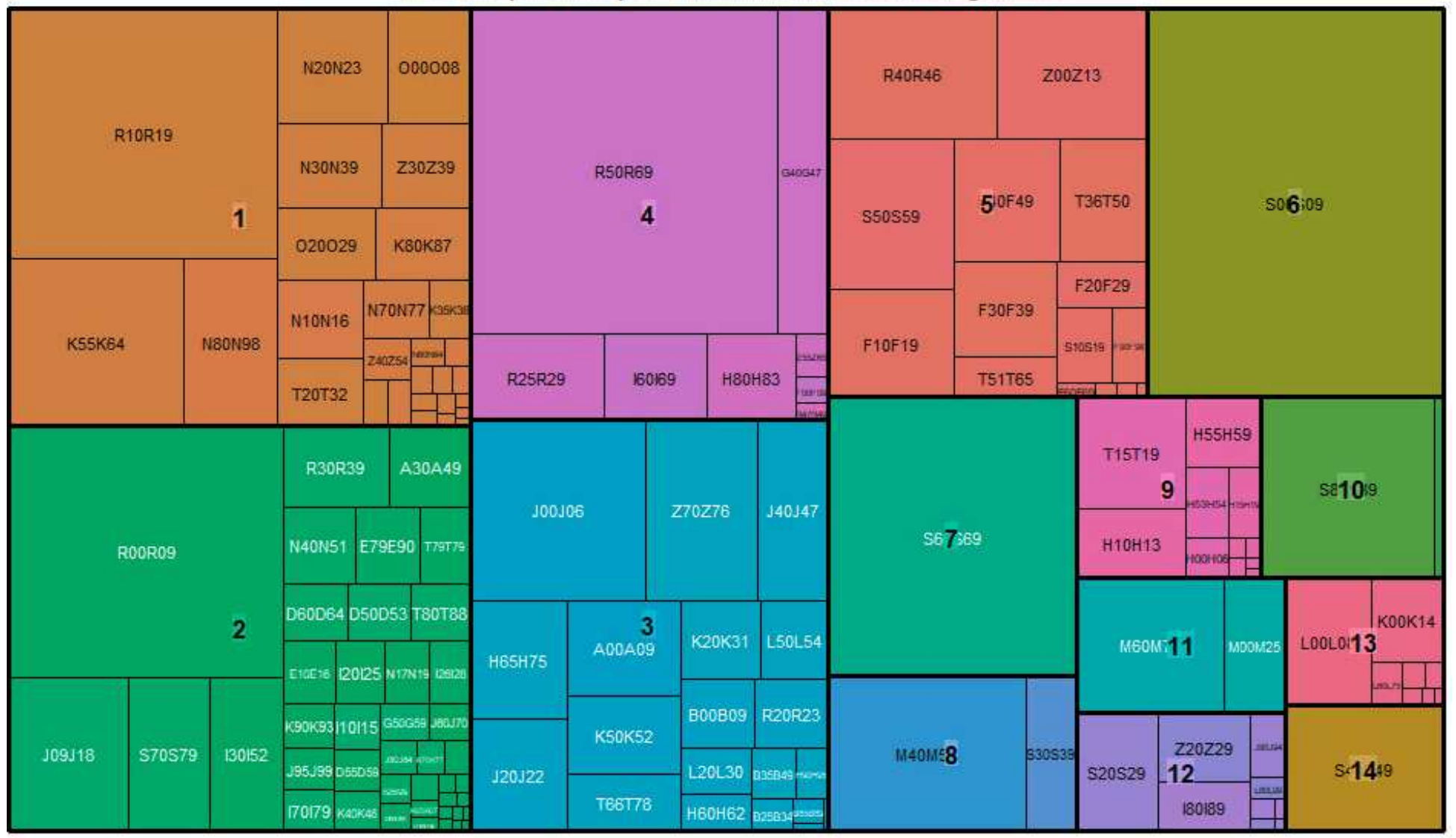

Figure 2

Distribution of blocks of diagnoses in the 14 clusters - Each cluster is represented by a unique colour. The volume of each area is proportional to the number of patients affected by the given block of diagnoses during the study period. The label of each block can be found at: https://www.icd10data.com/ICD10CM/Codes or in Supplementary Data Table S3 - Additional File 1 


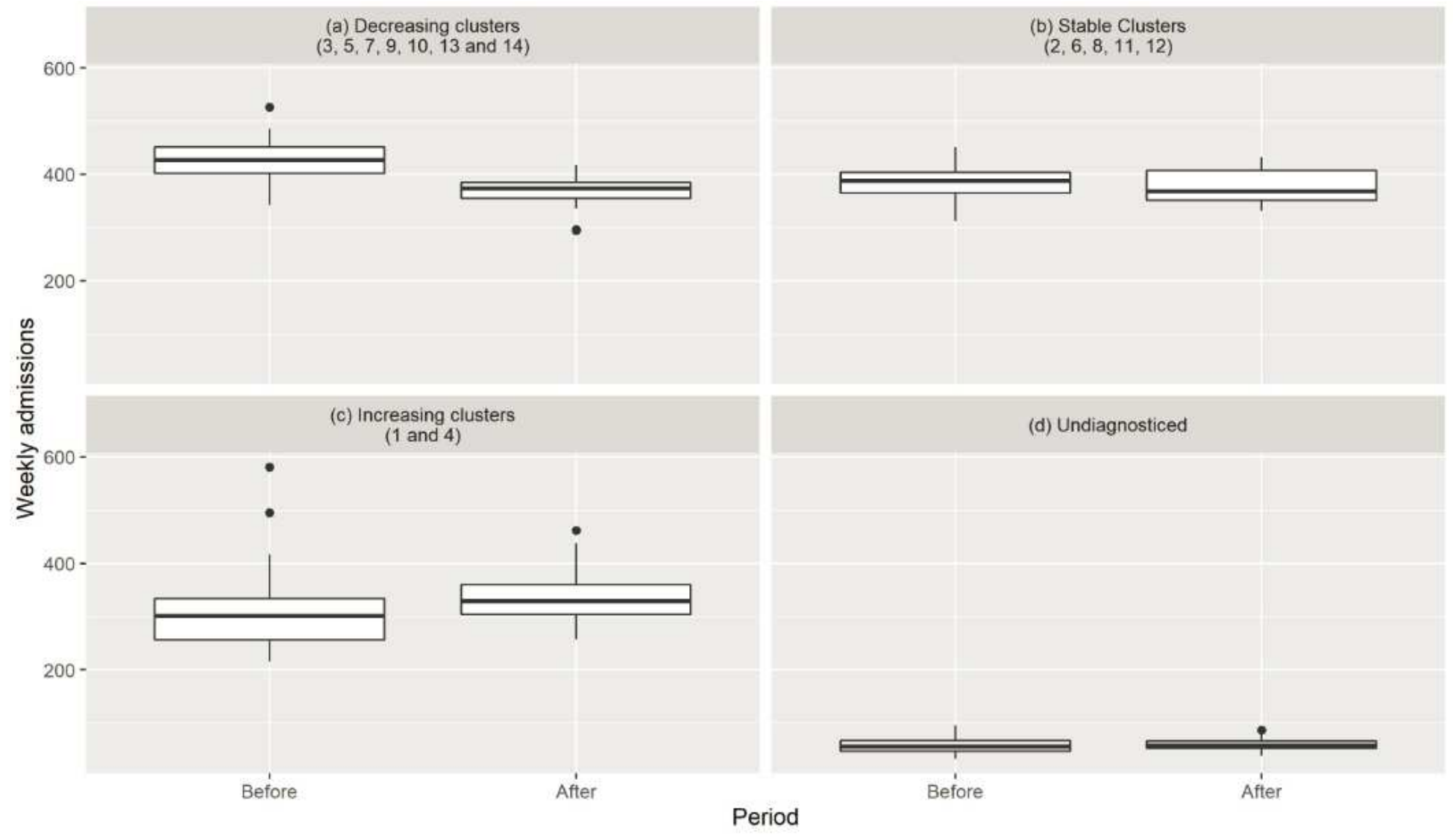

\section{Figure 3}

Trends in clusters before and after the opening of UCS - The numbers of weekly admissions are represented with boxplots where the middle line indicates the median, the boxes delimit the quartiles. The upper and lower whisker extends from the hinge to the largest and smallest (resp.) value no further than 1.5 * IQR from the hinge. (where IQR is the inter-quartile range, or distance between the first and third quartiles). 


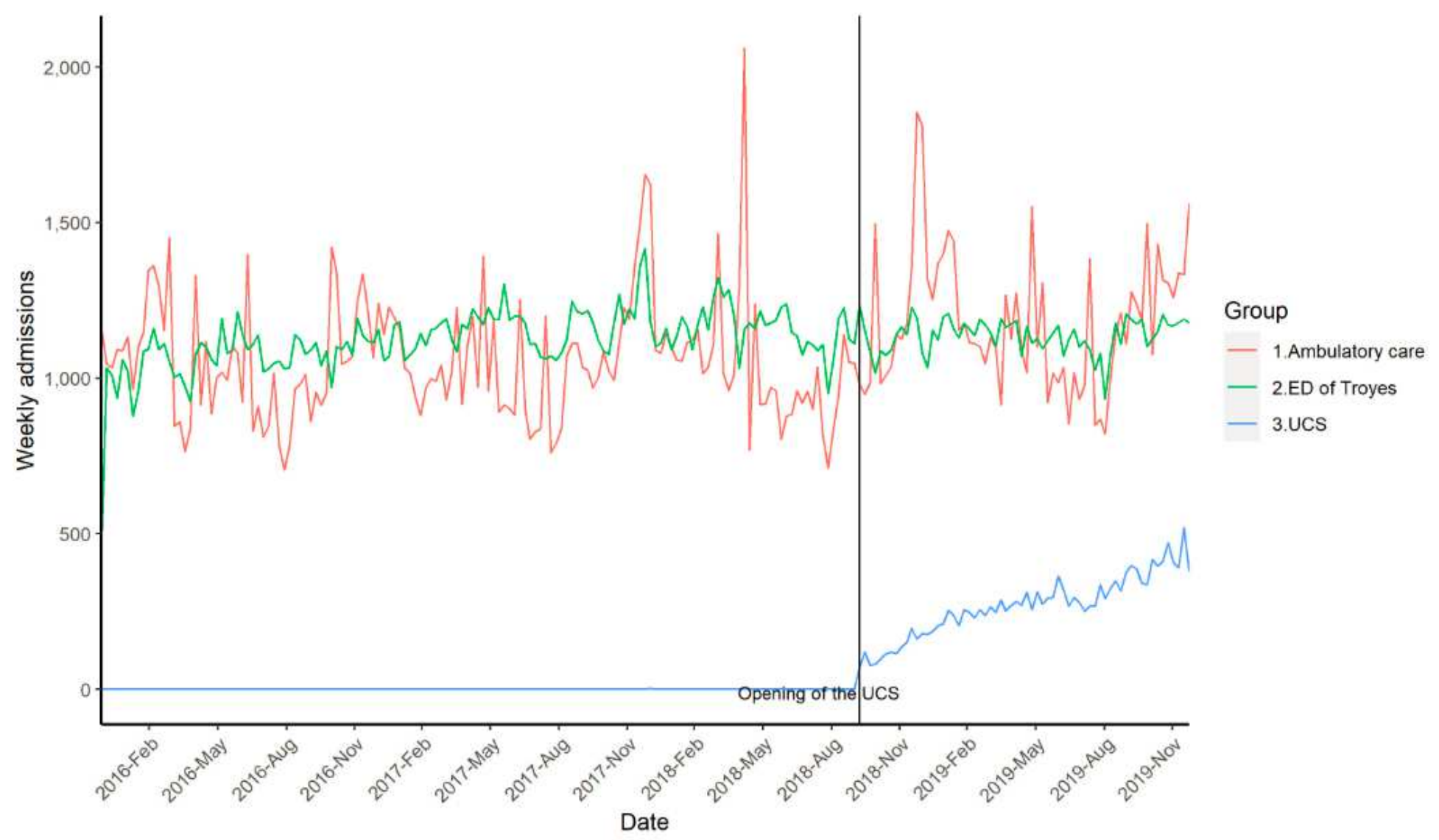

Figure 4

Trends in unscheduled care in the Aube Department, December 2015 - December 2019 - The numbers of weekly admissions is represented using lines for each type of unscheduled care surrounding the ED of Troyes. Ambulatory care is all the unscheduled consultations performed for the most part by general practitioners and nurses in the Aube territory via the SOS Médecin association and the Permanence Des Soins Ambulatoires (PDSA) registred in the Système Nationale des Données de Santé (SNDS, the national health information database).

\section{Supplementary Files}

This is a list of supplementary files associated with this preprint. Click to download.

- AdditionalFile1.docx 